\title{
Inactivation of Kallikrein in Human Plasma
}

\author{
Fedde van der Graaf, Johannes A. Koedam, and Bonno N. Bouma, \\ Department of Haematology, University Hospital Utrecht, \\ 3500 CG Utrecht, The Netherlands
}

\begin{abstract}
A B S T R A C T Human plasma kallikrein is inactivated by plasma protease inhibitors. This study was designed to determine the nature of these protease inhibitors and to assess their relative importance in the inactivation of kallikrein. Therefore, the kinetics of kallikrein inactivation and the formation of kallikrein inhibitor complexes were studied in normal plasma and in plasma depleted of either $\alpha_{2}$-macroglobulin $\left(\alpha_{2} \mathrm{M}\right)$, Cī inhibitor, or antithrombin (AT III). Prekallikrein was activated by incubation of plasma with dextran sulfate at $4^{\circ} \mathrm{C}$. After maximal activation, kallikrein was inactivated at $37^{\circ} \mathrm{C}$. Inhibition of kallikrein amidolytic activity in AT III-deficient plasma closely paralleled the inactivation rate of kallikrein in normal plasma. The inactivation rate of kallikrein in $\alpha_{2} \mathrm{M}$-deficient plasma was slightly decreased compared with normal plasma, but in contrast to normal, $C \overline{1}$ inhibitordeficient, and AT III-deficient plasma, no kallikrein amidolytic activity remained after inactivation that was resistant to inhibition by soybean trypsin inhibitor. Suppression of kallikrein activity in Cì inhibitor-deficient plasma was markedly decreased, and this was even more pronounced in plasma deficient in both Cī inhibitor and $\alpha_{2} \mathrm{M}$. The pseudo first-order rate constants for kallikrein inactivation in normal, AT III-deficient, $\alpha_{2} \mathrm{M}$-deficient, $\mathrm{C} \overline{\mathrm{l}}$ inhibitor-deficient plasma, and plasma deficient in both $\alpha_{2} \mathrm{M}$ and $\mathrm{C} \overline{\mathrm{l}}$ inhibitor, were $0.68,0.60,0.43,0.07$, and $0.016 \mathrm{~min}^{-1}$, respectively. Sodium dodecyl sulfate gradient polyacrylamide slab gel electrophoresis showed that during inactivation of kallikrein in plasma, high- $M_{\mathrm{r}}$ complexes were formed with $M_{\mathrm{r}}$ at 400,000-1,000,000, 185,000, and 125,000-135,000, which were identified as complexes of ${ }^{125} \mathrm{I}-\mathrm{kallikrein}$ with $\alpha_{2} \mathrm{M}, \mathrm{C} \overline{\mathrm{l}}$ inhibitor, and AT III, respectively. In addition, the presence of an unidentified kallikrein-inhibitor complex was observed in AT III-deficient plasma. $52 \%$ of the ${ }^{125}$ I-kallikrein was associated with Cli-inhibitor, $35 \%$ with $\alpha_{2} \mathrm{M}$, and
\end{abstract}

Address all correspondence to Dr. van der Graaf.

Received for publication 25 June 1982 and in revised form 30 September 1982.
$13 \%$ with AT III and another protease inhibitor. A similar distribution of ${ }^{125} \mathrm{I}$-kallikrein was observed when the ${ }^{125}$ I-kallikrein inhibitor complexes were removed from plasma by immunoadsorption with insolubilized anti-Cī inhibitor, anti- $\alpha_{2} \mathrm{M}$, or anti-AT III antibodies. These results suggest that only covalent complexes are formed between kallikrein and its inhibitors in plasma. As a function of time, ${ }^{125}$ I-kallikrein formed complexes with $\mathrm{C} \overline{1}$ inhibitor at a higher rate than with $\alpha_{2} \mathrm{M}$. No difference was observed between the inactivation rate of kallikrein in high- $M_{r}$ kininogen-deficient plasma and that in high- $M_{\mathrm{r}}$ kininogendeficient plasma reconstituted with high- $M_{r}$ kininogen; this suggests that high- $M_{\mathrm{r}}$ kininogen does not protect kallikrein from inactivation in the plasma milieu. These results have quantitatively demonstrated the major roles of $\mathrm{C} \overline{1}$ inhibitor and $\alpha_{2} \mathrm{M}$ in the inactivation of kallikrein in plasma.

\section{INTRODUCTION}

Plasma contains several protease inhibitors that are able to inactivate proteolytic enzymes. These plasma proteins regulate and modulate the involvement of several interrelated enzyme systems in various hemostatic and inflammatory reactions.

Plasma kallikrein, a serine protease, participates in these reactions. It releases bradykinin from kininogen (1), which increases the permeability of blood vessels, and mimics some features of the inflammatory response $(2,3)$. Kallikrein is also important in the contact phase mechanisms of the intrinsic blood clotting cascade and in the generation of fibrinolytic activity (4-8).

Five plasma proteinase inhibitors with varying potencies have thus far been identified as kallikrein inactivators: $C \overline{1}$ inhibitor, $\alpha_{2}$-macroglobulin $\left(\alpha_{2} M\right)^{1}$, antithrombin III (AT III), $\alpha_{1}$-antitrypsin, and $\alpha_{2}$-anti-

\footnotetext{
${ }^{1}$ Abbreviations used in this paper: $\alpha_{2} \mathrm{M}, \alpha_{2}$-macroglobulin; AT III, antithrombin III; HAE, hereditary angioedema; PAA, polyacrylamide; SBTI, soybean trypsin inhibitor.
} 
plasmin (9-17). Cī inhibitor and $\alpha_{2} \mathrm{M}$ are suggested to be important inactivators of plasma kallikrein (915). The suggestion that $C \bar{l}$ inhibitor is a major inhibitor of kallikrein in plasma was based on the observation that plasma from individuals with hereditary angioneurotic edema showed a markedly decreased inhibition toward kallikrein esterolytic and amidolytic activity compared with normal plasma $(11,14,15)$. Another study (10) indicated that $\alpha_{2} \mathrm{M}$ also contributes a substantial part of the inactivation of kallikrein in human plasma. All these studies, however, did not show the formation of complexes between kallikrein and its inhibitors in plasma, nor was the quantitative contribution of the various inhibitors to the inactivation of kallikrein in plasma determined. The present study was designed to identify the kallikrein inhibitors, to characterize the complexes formed between kallikrein and its inhibitors in plasma, and to establish the relative importance of each inhibitor for the inactivation of kallikrein in plasma.

\section{METHODS}

Prekallikrein, Factor XII, high- $M_{\mathrm{r}}$ kininogen, CĪ inhibitor, ${ }^{2}$ $\alpha_{2} \mathrm{M},{ }^{2}$ and AT III ${ }^{3}$ were isolated from human plasma as described elsewhere (18-20). Kallikrein was prepared from prekallikrein by incubation with $\beta$-Factor $\mathrm{XII}_{\mathrm{a}}$ (Hageman factor fragment, $\mathrm{HF}_{\mathrm{f}}$, the $28,000-M_{\mathrm{r}}$ form of activated $\mathrm{Fac}$ tor XII). After activation of prekallikrein, $\beta$-Factor $\mathrm{XII}_{\mathrm{a}}$ was removed by affinity chromatography on $\mathrm{CNBr}$-activated Sepharose $4 \mathrm{~B}$ to which immunopurified anti-Factor XII antibodies were covalently coupled as previously described (21). In the absence of reducing agents, the kallikrein preparation gave two protein bands on sodium dodecyl sulfate (SDS) polyacrylamide (PAA) gels with $M_{\mathrm{r}}=80,000$ and three fragments with $M_{\mathrm{r}}=43,000,36,000$, and 33,000 on reduced SDS PAA gels. The specific amidolytic activity of kallikrein was $19.3 \mu \mathrm{mol} \mathrm{min}{ }^{-1} \mathrm{mg}^{-1}$ using benzoyl-Pro-Phe-Arg- $p$-nitroanilide (Chromozym PK, Boehringer, Mannheim, West Germany) as a substrate in a concentration of $0.166 \mathrm{mM}$ in 0.1 $\mathrm{M}$ Tris, $0.05 \mathrm{M} \mathrm{NaCl}, \mathrm{pH} 8.0$ at $37^{\circ} \mathrm{C}$. Radiolabeling of prekallikrein and kallikrein was performed with ${ }^{125} \mathrm{I}$ by using the Bolton-Hunter reagent (22). The prekallikrein preparation retained its procoagulant activity after the radiolabeling procedure, and the specific radioactivity was $0.9 \mu \mathrm{Ci}$ / $\mu \mathrm{g}$. Kallikrein was radiolabeled in the presence of $1 \mathrm{mM}$ benzamidine. After the radiolabeling procedure, benzamidine was removed by extensive dialysis. The radiolabeled kallikrein retained at least $60 \%$ of its specific amidolytic activity and contained $0.6 \mu \mathrm{Ci} / \mu \mathrm{g}$. Radioactivity was measured in a Packard 5110 gammacounter (Packard Instrument Co., Inc., Downers Grove, IL). All purified proteins were stored at $-70^{\circ} \mathrm{C}$ in storage buffer $(5 \mathrm{mM}$ sodium acetate, $0.15 \mathrm{M}$ $\mathrm{NaCl}, 0.02 \% \mathrm{NaN}_{3}, \mathrm{pH} 5.3$ ).

\footnotetext{
${ }^{2}$ F. van der Graaf, A. Rietveld, and B. N. Bouma. Manuscript in preparation.

${ }^{3}$ C. de Swart, A. Nijmeyer, J. J. Sixma, and B. N. Bouma. Manuscript in preparation.
}

Antibodies directed against $\alpha_{2} \mathrm{M}$ or AT III were prepared by four successive weekly injections of $25 \mu \mathrm{g}$ of $\alpha_{2} \mathrm{M}$ or AT III in complete Freund's adjuvant (Difco Laboratories, Detroit, MI) into a goat at multiple subcutaneous sites. AntiCĪ inhibitor antiserum was obtained from Behring-Werke AG, Marburg/Lahn, West Germany.

Immunopurified antibodies were prepared by affinity chromatography of the different antisera on a column of $\mathrm{CNBr}$-activated Sepharose $4 \mathrm{~B}(\mathrm{lg})$ to which either purified $\alpha_{2} \mathrm{M}(5 \mathrm{mg}), \mathrm{C} \overline{\mathrm{l}}$ inhibitor $(2.8 \mathrm{mg})$, or AT III $(4.6 \mathrm{mg})$ was covalently coupled. The antibodies were eluted with $3 \mathrm{M}$ KSCN in $0.01 \mathrm{M}$ sodium phosphate, $0.5 \mathrm{M} \mathrm{NaCl}, \mathrm{pH} 7.4$ and

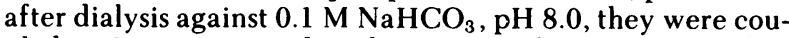
pled to CNBr-activated Sepharose 4B. The immunopurified antibodies against $\alpha_{2} \mathrm{M}, \mathrm{C} \overline{\mathrm{I}}$ inhibitor, or AT III gave one precipitation line against normal human plasma; this showed a reaction of identity with the single line obtained against purified human $\alpha_{2} \mathrm{M}, \mathrm{C} \overline{\mathrm{I}}$ inhibitor, or AT III, respectively. $\alpha_{2} \mathrm{M}$ - or Cī inhibitor-deficient plasma was prepared by immunoadsorption of $\alpha_{2} \mathrm{M}$ or Ci inhibitor from Factor XIIdeficient plasma by using a column of $\mathrm{CNBr}$-activated Sepharose 4B $(2 \mathrm{~g})$ to which immunopurified anti-Ci inhibitor $(9.4 \mathrm{mg})$ or anti- $\alpha_{2} \mathrm{M}(17.5 \mathrm{mg})$ antibodies were covalently coupled. $5 \mathrm{ml}$ of $\mathrm{C} \overline{1}$ inhibitor-deficient and $4.5 \mathrm{ml}$ of $\alpha_{2} \mathrm{M}$ deficient plasma were obtained. Plasma deficient in both Cī inhibitor and $\alpha_{2} \mathrm{M}$ was prepared by immunoadsorption of $\alpha_{2} \mathrm{M}$ and Ci inhibitor, respectively, from the same Factor XII-deficient plasma. AT III-deficient plasma was prepared by immunoadsorption of AT III from normal human plasma with a column of immunopurified anti-AT III antibodies (14.6 mg) covalently coupled to $2 \mathrm{~g}$ of $\mathrm{CNBr}$-activated Sepharose $4 \mathrm{~B} .10 \mathrm{ml}$ of AT III-deficient plasma was obtained. The $\alpha_{2} \mathrm{M}$-deficient, Ci inhibitor-deficient, and AT III-deficient plasmas, and plasma deficient in both $\alpha_{2} \mathrm{M}$ and Cī inhibitor, were completely depleted of the respective appropriate inhibitor $(<1 \%)$ as measured by Laurell rocket immunoelectrophoresis (23). The other inhibitors that were not removed by immunoadsorption remained at normal plasma levels. Also prekallikrein and high- $M_{\mathrm{r}}$ kininogen levels were at normal plasma concentrations as was Factor XII in AT III-deficient plasma. Prekallikrein, high- $M_{r}$ kininogen, and Factor XII were determined by using partial thromboplastin time assays (8). High- $M_{\mathrm{r}}$ kininogen-deficient plasma was obtained from George King, Bio-Medical Inc. (Overland Park, KS) and from a congenitally deficient patient. ${ }^{4}$ Factor XII-deficient plasma was from a congenitally deficient patient. A normal plasma pool of citrated plasma was obtained from 40 healthy donors. The plasmas were stored frozen at $-70^{\circ} \mathrm{C}$.

PAA gel electrophoresis in the presence of SDS was carried out on $3-25 \%$ gradient slab gels $(280 \times 140 \times 0.75 \mathrm{~mm})$ after the method of Laemmli (24). The gels were run at $150 \mathrm{~V}$, $25 \mathrm{~mA}$, for $18 \mathrm{~h}$, using running tap water for cooling. The gels were stained for protein with Coomassie blue R-250 and subsequently dried on Whatman 3-MM paper (Whatman Inc., Paper Div., Clifton, NJ). Autoradiography of the dried slab gels was performed using Sakura $x$-ray film A (Konishiraku Photo Inc., Co., Ltd, Tokyo). The dried gel was cut longitudinally, sliced into sections $(13 \times 3 \mathrm{~mm})$, and then counted for radioactivity. The following standard proteins were included as references on each slab gel: myosin $\left(M_{\mathrm{r}}=200,000\right), \beta$-galactosidase $\left(M_{\mathrm{r}}=116,500\right)$, phosphor-

${ }^{4}$ O. Ch. Leeksma, J. A. van Mourik, and B. N. Bouma. Manuscript in preparation. 
ylase b $\left(M_{\mathrm{r}}=94,000\right)$, bovine serum albumin $\left(M_{\mathrm{r}}=67,000\right)$, ovalbumin $\left(M_{\mathrm{r}}=43,000\right)$, and carbonic anhydrase $\left(M_{\mathrm{r}}\right.$ $=30,000)($ Bio-Rad Laboratories, Richmond, CA).

Inhibition of kallikrein in normal and various inhibitordeficient plasmas. Because most protease inhibitor-deficient plasmas were prepared from Factor XII-deficient plasma, purified Factor XII was added to these plasmas to obtain a final concentration of $1 \mathrm{U} / \mathrm{ml}$ in order to obtain a normal generation of kallikrein activity induced by dextran sulfate. $382.5 \mu \mathrm{l}$ of Factor XII-deficient, $\alpha_{2} \mathrm{M}$-deficient, Cī inhibitor-deficient plasma, and plasma deficient in both $\mathrm{C} \overline{1}$ inhibitor and $\alpha_{2} \mathrm{M}$ were mixed at $4^{\circ} \mathrm{C}$ with $67.5 \mu \mathrm{l}$ of purified Factor XII $(13.5 \mu \mathrm{g})$. Because AT III-deficient plasma was prepared from normal plasma, $67.5 \mu$ l of storage buffer was added to $382.5 \mu \mathrm{l}$ of AT III deficient-plasma. 450 $\mu$ l of dextran sulfate $\left(25 \mu \mathrm{g} / \mathrm{ml}, M_{\mathrm{r}}=500,000\right.$, Pharmacia Fine Chemicals AB, Uppsala, Sweden) was then added and incubated at $4^{\circ} \mathrm{C}$ for $12 \mathrm{~min}$. Before the mixture was incubated at $37^{\circ} \mathrm{C}$, two samples of $30 \mu \mathrm{l}$ were withdrawn. One sample was immediately added to a cuvette containing $1 \mathrm{ml}$ of $0.166 \mathrm{mM}$ Chromozym PK and measured for total kallikrein amidolytic activity, and the other sample was immediately mixed with $10 \mu$ l of a soybean trypsin inhibitor solution (SBTI, $10 \mathrm{mg} / \mathrm{ml}$, Sigma Chemical Co., St. Louis, MO) at $37^{\circ} \mathrm{C}$, and after $15 \mathrm{~s}$ tested for remaining kallikrein amidolytic activity. $30-\mu \mathrm{l}$ aliquots were removed from the incubation mixture at various times and measured for total and remaining kallikrein amidolytic activity. Free kallikrein amidolytic activity was calculated by subtraction of the activity that was resistant to SBTI (the remaining kallikrein activity) from the total kallikrein activity measured in the absence of SBTI. Kallikrein amidolytic activity was measured spectrophotometrically as the initial rate of hydrolysis of benzoyl-Pro-Phe-Arg- $p$-nitroanilide (Chromozym PK) by using a Beckman model 3600 double-beam spectrophotometer (Beckman Instruments, Inc., Fullerton, CA). The change in absorbance at $405 \mathrm{~nm}$ was followed and the initial velocity was measured to give $\Delta A / \mathrm{min}$, where $A$ is absorbance. The observed $\Delta A / \mathrm{min}$ was converted to percent by comparison with the maximum $\Delta A / \mathrm{min}$ obtained in the various plasmas.

3-25\% gradient SDS-PAA gel electrophoresis analysis of ${ }^{125}$ I-kallikrein inactivated in normal and various inhibitor deficient plasmas. $6 \mu \mathrm{l}$ of ${ }^{125} \mathrm{I}-\mathrm{kallikrein}(0.9 \mu \mathrm{Ci})$ was added to $24 \mu \mathrm{l}$ of Factor XII-deficient, $C \overline{1}$ inhibitor-deficient, $\alpha_{2} \mathrm{M}$ deficient, AT III-deficient plasma, and plasma deficient in both $\alpha_{2} \mathrm{M}$ and $\mathrm{C} \overline{\mathrm{I}}$ inhibitor and incubated at $37^{\circ} \mathrm{C}$. After inactivation of kallikrein, $7.5 \mu \mathrm{l}$ of the incubation mixture

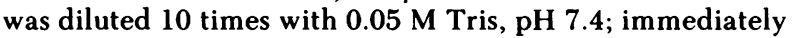
mixed with an equal volume of $0.125 \mathrm{M}$ Tris, $\mathrm{pH} 6.8,4 \%$ SDS, and $10 \%$ glycerol; and incubated for $60 \mathrm{~min}$ at $37^{\circ} \mathrm{C}$. $50 \mu \mathrm{l}$ of this mixture was then applied to an SDS $3-25 \%$ gradient PAA slab gel. For the inactivation of kallikrein with purified proteins, $1.3 \mu \mathrm{g}$ of ${ }^{125} \mathrm{I}$-kallikrein was incubated with either $3.6 \mu \mathrm{g}$ of $\mathrm{C} \overline{1}$ inhibitor, $50.1 \mu \mathrm{g}$ of $\alpha_{2} \mathrm{M}$, or $4.0 \mu \mathrm{g}$ of AT III in $0.05 \mathrm{M}$ Tris, $0.15 \mathrm{M} \mathrm{NaCl}, \mathrm{pH} 7.4$ in a final volume of $25 \mu \mathrm{l}$ at $37^{\circ} \mathrm{C}$. $7.5 \mu \mathrm{l}$ of the mixture was then diluted 10 times with $0.05 \mathrm{M}$ Tris, $\mathrm{pH} 7.4$; immediately mixed with an equal volume of $0.125 \mathrm{M}$ Tris, pH $6.8,4 \%$ SDS, and $10 \%$ glycerol; and incubated for $60 \mathrm{~min}$ at $37^{\circ} \mathrm{C} .50 \mu \mathrm{l}$ of this mixture was subsequently applied to the same SDS $3-25 \%$ gradient PAA slab gel as the plasma samples. Electrophoresis was performed for $18 \mathrm{~h}$. After autoradiography, the dried gel was sliced into sections and counted for radioactivity. The contribution of the different inhibitors to complex formation with kallikrein in plasma was determined by analysis of the gel patterns.
Analysis of the contribution of different inhibitors to kallikrein inactivation using insolubilized anti-CI inhibitor, anti- $\alpha_{2} M$, and anti-AT III antibodies. $1 \mathrm{ml}$ of normal plasma was incubated with $70 \mu \mathrm{l}$ of dextran sulfate $(1 \mathrm{mg}$ $\mathrm{ml})$ at $4^{\circ} \mathrm{C}$. After $7 \mathrm{~min}, 20 \mu \mathrm{l}$ of ${ }^{125} \mathrm{I}$-kallikrein $(3 \mu \mathrm{Ci})$ was added to the plasma followed by incubation at $37^{\circ} \mathrm{C}$ for 20 min. $200 \mu \mathrm{l}$ of this mixture was applied to a column containing $\mathrm{CNBr}$-activated Sepharose $4 \mathrm{~B}(0.5 \mathrm{~g})$ to which antiCī inhibitor (1.8 mg), anti- $\alpha_{2} \mathrm{M}(4.4 \mathrm{mg})$, or anti-AT III $(2.9$ $\mathrm{mg}$ ) antibodies had been coupled. After washing the column with eight bed-volumes of $0.05 \mathrm{M}$ sodium phosphate and 0.5 $\mathrm{M} \mathrm{NaCl}, \mathrm{pH} 7.0$, the total content of each column was counted for bound radioactivity. The radioactivity bound was corrected for the radioactivity bound to $\mathrm{CNBr}$-activated Sepharose 4B to which no antibodies were coupled. The material that did not adhere to each column was tested for the presence of kallikrein amidolytic activity and of $C \bar{l}$ inhibitor, $\alpha_{2} \mathrm{M}$, and AT III by immunodiffusion with anti-CI inhibitor, anti- $\alpha_{2} \mathrm{M}$, or anti-AT III antiserum.

Kinetics of ${ }^{125}$ I-kallikrein inhibitor complex formation in normal human plasma. $15 \mu \mathrm{l}$ of ${ }^{125} \mathrm{I}$-prekallikrein $(4.0 \mu \mathrm{Ci})$ was added to $100 \mu \mathrm{l}$ of normal human plasma followed by activation with $7 \mu$ l of dextran sulfate $(1 \mathrm{mg} / \mathrm{ml})$ for $20 \mathrm{~min}$ at $4^{\circ} \mathrm{C}$. Under these conditions, all ${ }^{125} \mathrm{I}$-prekallikrein was converted to ${ }^{125} \mathrm{I}$-kallikrein. This mixture was incubated at $37^{\circ} \mathrm{C}$ and at various times a $10-\mu \mathrm{l}$ aliquot was removed and added to $390 \mu \mathrm{l}$ of $0.07 \mathrm{M}$ Tris, $\mathrm{pH} 6.8,2 \%$ SDS, and $5 \%$ glycerol. $50 \mu \mathrm{l}$ of this mixture was used for analysis by SDS $3-25 \%$ gradient PAA slab gel electrophoresis. The contribution of the different inhibitors to complex formation with kallikrein was determined as described above.

Inactivation of kallikrein in high-Mr kininogen-defcient plasma. $12 \mu \mathrm{l}$ of kallikrein $(5.1 \mu \mathrm{g})$ was mixed at $4^{\circ} \mathrm{C}$ with different volumes $(0,10.3$, and $20.6 \mu \mathrm{l})$ of storage buffer and different volumes $(20.6,10.3$, and $0 \mu \mathrm{l})$ of high- $M_{\mathrm{r}}$ kininogen $(675 \mu \mathrm{g} / \mathrm{ml})$. The total volume of storage buffer and high- $M_{\mathrm{r}}$ kininogen was always $20.6 \mu \mathrm{l}$. After $5 \mathrm{~min}, 100 \mu \mathrm{l}$ of high-M $M_{r}$ kininogen-deficient plasma was added and mixed. $15 \mu \mathrm{l}$ of this mixture was removed and added to a cuvette containing $1 \mathrm{ml}$ of Chromozym PK to test for kallikrein amidolytic activity. The mixture was subsequently placed at $37^{\circ} \mathrm{C}$ and at various times $15-\mu$ l aliquots were tested for kallikrein amidolytic activity. The $\Delta A / \mathrm{min}$ was converted to percent by comparison with the $\Delta A / \mathrm{min}$ of the zero time sample removed before placing the mixture at $37^{\circ} \mathrm{C}$.

\section{RESULTS}

Kinetics of kallikrein inactivation in normal and inhibitor-deficient plasmas. To investigate the inactivation of kallikrein in various inhibitor-deficient plasmas, the plasmas which were prepared from Factor XII-deficient plasma were first reconstituted with purified Factor XII to normal values and then incubated with dextran sulfate at $4^{\circ} \mathrm{C}$. After generation of maximum kallikrein activity, the plasmas were incubated at $37^{\circ} \mathrm{C}$ and the inactivation of kallikrein was followed by measurement of the kallikrein amidolytic activity at several times. A rapid decrease of total and free kallikrein amidolytic activity in normal plasma was observed (Fig. 1A). The difference between total 


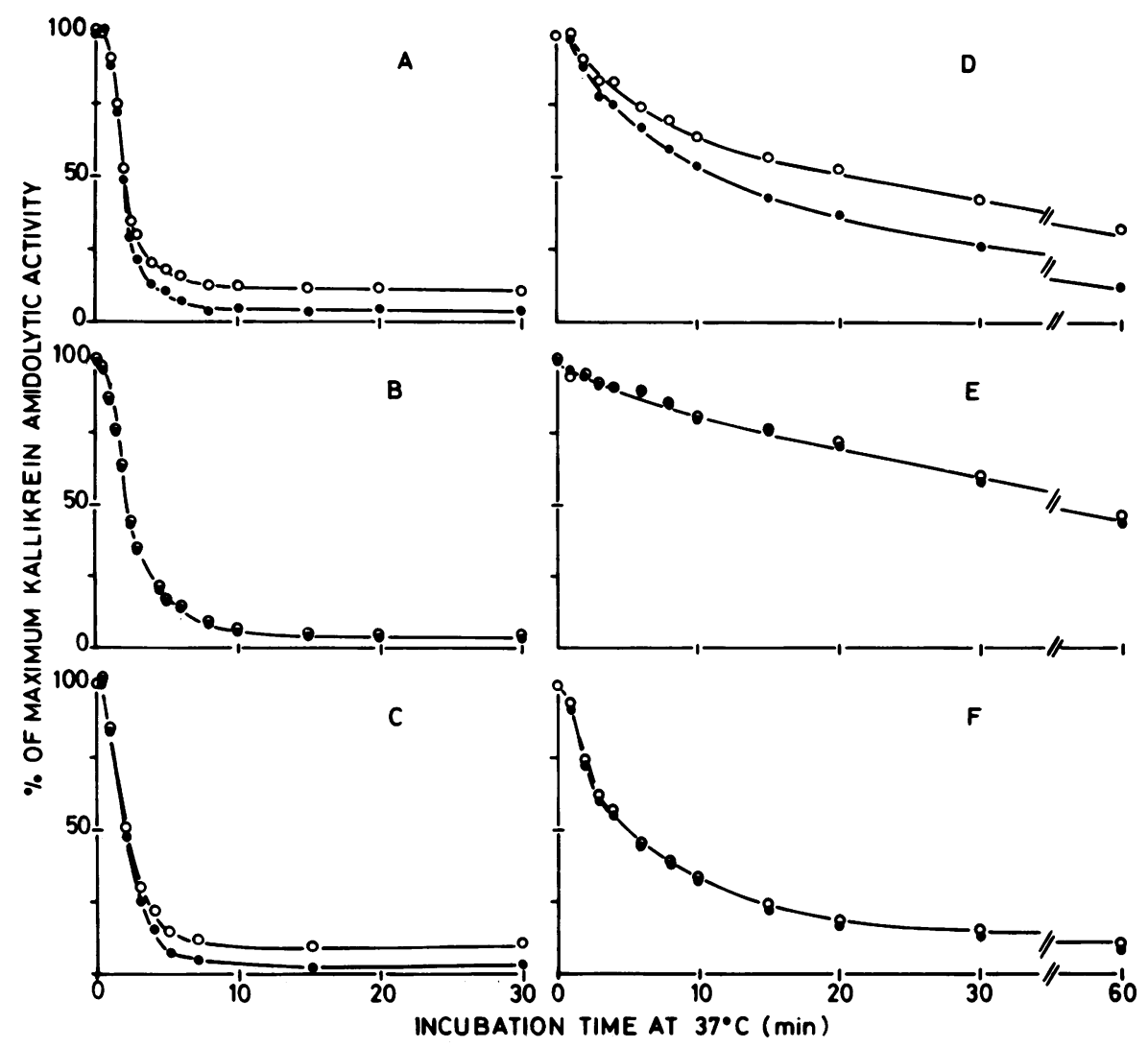

FIGURE 1 Inhibition of total $(O)$ and free $(\bullet)$ kallikrein amidolytic activity in various inhibitordeficient plasmas. Activation of prekallikrein in plasma was initiated by addition of dextran sulfate at $4^{\circ} \mathrm{C}$. Inactivation of kallikrein $(0.31 \mu \mathrm{M})$ was then followed at $37^{\circ} \mathrm{C}$. At various times, $30-\mu$ l aliquots were tested for kallikrein amidolytic activity (total kallikrein activity) and for SBTI-inhibitable amidolytic activity (free kallikrein activity), as described in Methods. A, normal human plasma; B, $\alpha_{2} \mathrm{M}$-deficient plasma; C, AT III-deficient plasma; D, Cì inhibitordeficient plasma; E, plasma deficient in both $C \overline{1}$ inhibitor and $\alpha_{2} \mathrm{M} ; \mathrm{F}$, plasma deficient in $\mathrm{C} \overline{\mathrm{I}}$ inhibitor and $\alpha_{2} \mathrm{M}$ to which heparin $(100 \mathrm{U} / \mathrm{ml})$ was added after generation of maximum kallikrein amidolytic activity.

and free kallikrein amidolytic activity is the SBTI-resistant kallikrein amidolytic activity (see Methods). After $\sim 5 \mathrm{~min}$, a plateau of total kallikrein activity was reached at $11 \%$ of the original activity. Inactivation of kallikrein activity (total and free) in AT III-deficient plasma (Fig. 1C) closely paralleled the inactivation patterns observed in normal plasma. The rate of kallikrein inactivation in $\alpha_{2} \mathrm{M}$-deficient plasma (Fig. 1B) was slightly decreased compared with normal plasma, but in contrast to normal, $C \bar{l}$ inhibitor, and AT III-deficient plasma there was no difference between total and free kallikrein amidolytic activity. Furthermore, kallikrein amidolytic activity was almost completely $(<2 \%)$ inactivated in this plasma. This suggests that the difference between total and free kallikrein amidolytic activity as observed in normal plasma is caused by $\alpha_{2} \mathrm{M}$-bound kallikrein that still expresses some amidolytic activity, and which is not inhibitable by SBTI. Using purified proteins we have shown that this $\alpha_{2} \mathrm{M}$-bound kallikrein amidolytic activity represents one-fourth of the amidolytic activity of the free kallikrein when measured at a concentration of $0.166 \mathrm{mM}$ Chromozym PK. ${ }^{2}$ Suppression of kallikrein activity in Cī inhibitor-deficient plasma (Fig. 1D) and in plasma deficient in both Cİ inhibitor and $\alpha_{2} \mathrm{M}$ (Fig. 1E) was markedly decreased. After a 1-h incubation at $37^{\circ} \mathrm{C}, 32 \%$ of total kallikrein amidolytic activity was still present in Cī inhibitor-deficient plasma. The difference between total and free kallikrein amidolytic activity in this plasma was even more pronounced than in normal plasma, indicating that more kallikrein was inactivated by $\alpha_{2} \mathrm{M}$ than in 
normal plasma. Addition of heparin $(100 \mathrm{U} / \mathrm{ml})$ to plasma deficient in both $\alpha_{2} \mathrm{M}$ and $\mathrm{C} \bar{l}$ inhibitor led to a marked increase in the rate and extent of inactivation of kallikrein, which suggests that AT III was the major inhibitor in the presence of heparin (Fig. 1F).

When $\ln \left([\mathrm{Kal}]_{0} /[\mathrm{Kal}]_{t}\right)$ for the different inactivation curves was plotted against the incubation time at $37^{\circ} \mathrm{C}$, a straight line was obtained, indicating that the inactivation of free kallikrein amidolytic activity in the various plasmas followed pseudo first-order kinetics (Fig. 2). The slope of each line is the pseudo first-order rate constant, which for the inactivation of kallikrein in normal, AT III-deficient, $\alpha_{2}$ M-deficient, Cī inhibitor-deficient plasma, and plasma deficient in both $\alpha_{2} \mathrm{M}$ and $\mathrm{C} \overline{\mathrm{l}}$ inhibitor, was $0.68,0.60,0.43,0.07$; and $0.016 \mathrm{~min}^{-1}$, respectively. Addition of heparin to plasma deficient in both $\alpha_{2} \mathrm{M}$ and $\mathrm{C} \overline{\mathrm{l}}$ inhibitor increased the pseudo first-order rate constant eightfold to $0.13 \mathrm{~min}^{-1}$.

Kallikrein-inhibitor complex formation: analysis by SDS 3-25\% gradient PAA slab gel electrophoresis. To study complex formation between kallikrein and its inhibitors, ${ }^{125} \mathrm{I}-\mathrm{kallikrein}$ was added to normal and various inhibitor-deficient plasmas followed by inactivation at $37^{\circ} \mathrm{C}$. Plasma samples were then subjected to SDS 3-25\% gradient PAA slab gel electrophoresis. To identify the complexes formed in plasma, ${ }^{125} \mathrm{I}-\mathrm{kal}-$

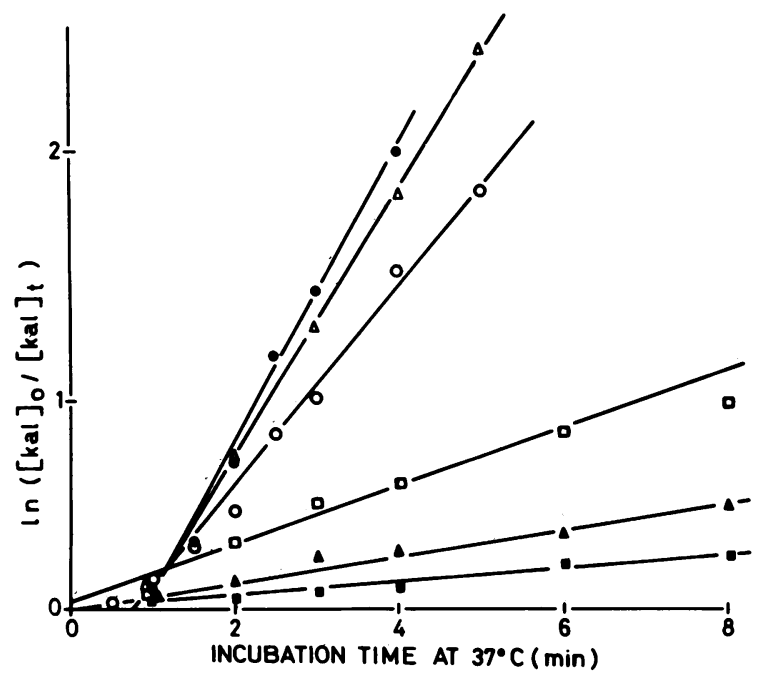

Ficure 2 Kinetics of inactivation of free kallikrein amidolytic activity in normal plasma (৩), AT III-deficient plasma $(\Delta), \alpha_{2} \mathrm{M}$-deficient plasma $(O)$, plasma deficient in both $\mathrm{CI}$ inhibitor and $\alpha_{2} \mathrm{M}$ with heparin (ם), CI inhibitordeficient plasma $(\Delta)$, and plasma deficient in both $C \overline{1}$ inhibitor and $\alpha_{2} \mathrm{M}(\boldsymbol{\square})$ plotted as $\ln \left([\mathrm{Kal}]_{0} /[\mathrm{Kal}]_{t}\right)$ against incubation time at $37^{\circ} \mathrm{C}$. [Kal $]_{0}$, kallikrein concentration at 0 min incubation at $37^{\circ} \mathrm{C} ;[\mathrm{Kal}]_{t}$, kallikrein concentration at $t$ min incubation at $37^{\circ} \mathrm{C}$. likrein was incubated simultaneously with either purified $\mathrm{C} \overline{1}$ inhibitor, $\alpha_{2} \mathrm{M}$, or AT III and analyzed on the same gel. After autoradiography of the gel, the contribution of the different inhibitors to the inactivation of kallikrein in the various plasmas was calculated by counting the radioactivity incorporated in the SDS-resistant ${ }^{125}$ I-kallikrein-inhibitor complexes. Fig. 3 shows the autoradiogram. Approximately $45 \%$ of the radioactivity in all samples remained at $\boldsymbol{M}_{\mathrm{r}}$ $=80,000$, suggesting that this portion of the radiolabeled kallikrein was inactive or was released from noncovalent complexes. $55 \%$ of the radioactivity in normal plasma was associated with a number of bands: one band with apparent $M_{\mathrm{r}}$ of 185,000 ; several bands in $M_{\mathrm{r}}$ range of $\sim 400,000-1,000,000$; and three faint bands with an $M_{r}$ of $125,000,130,000$, and 135,000 (Fig. 3A). The complexes with $M_{r}=400,000$ $1,000,000$ probably resulted from complex formation between $\alpha_{2} \mathrm{M}$ and ${ }^{125} \mathrm{I}$-kallikrein, because purified $\alpha_{2} \mathrm{M}$ and ${ }^{125}$ I-kallikrein formed apparently identical complexes (Fig. 3C), whereas these bands were not present in $\alpha_{2} \mathrm{M}$-deficient plasma (Fig. 3B). The band with $M_{\mathrm{r}}=185,000$ in normal plasma corresponded to the complex formed between ${ }^{125} \mathrm{I}$-kallikrein and purified Cì inhibitor (Fig. 3E), suggesting that in normal plasma this band is derived from complex formation

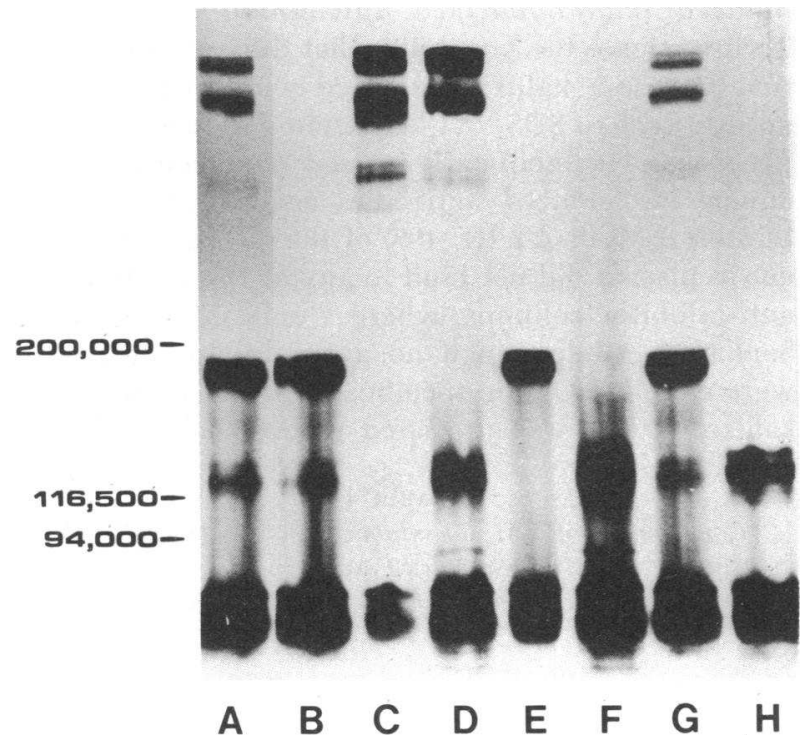

FIgURE 3 Autoradiogram of a SDS 3-25\% gradient PAA slab gel containing mixtures of ${ }^{125} \mathrm{I}$-kallikrein incubated for different times at $37^{\circ} \mathrm{C}$ with $\mathrm{A}$, normal human plasma (20 min); B, $\alpha_{2} \mathrm{M}$-deficient plasma $(20 \mathrm{~min})$; C, purified $\alpha_{2} \mathrm{M}$ (60 min); D, CĪ inhibitor-deficient plasma (180 min); $E$, purified CI inhibitor ( $30 \mathrm{~min}$ ); $\mathrm{F}$, plasma deficient in both $\alpha_{2} \mathrm{M}$ and CI inhibitor (240 min); G, AT III-deficient plasma $(20 \mathrm{~min})$; and $\mathrm{H}$, purified AT III $(60 \mathrm{~min})$. 
between kallikrein and $C \bar{I}$ inhibitor. Further evidence for this is obtained from the fact that this band was absent in $\mathrm{C} \overline{\mathrm{I}}$ inhibitor-deficient plasma (Fig. 3D). The three faint bands with $M_{\mathrm{r}}=125,000,130,000$, and 135,000 seen in normal plasma were apparently identical to those seen when ${ }^{125}$ I-kallikrein formed complexes with purified AT III (Fig. 3H). These bands were the only kallikrein-inhibitor complexes seen in plasma deficient in both $\alpha_{2} \mathrm{M}$ and $\mathrm{CI}$ inhibitor (Fig. $3 \mathrm{~F})$. However, when ${ }^{125} \mathrm{I}-$ kallikrein was inactivated in AT III-deficient plasma, the same three bands were apparently formed. As no AT III antigen was detectable in this plasma $(<1 \%)$, this suggests that during inactivation of kallikrein in plasma, complexes with $M_{r}=125,000-135,000$ are formed between kallikrein and an inhibitor other than AT III. Table I lists the contribution of $\mathrm{C} \overline{1}$ inhibitor, $\alpha_{2} \mathrm{M}$, and AT III to kallikrein complex formation in normal and various inhibitor-deficient plasmas. $52 \%$ of the active ${ }^{125} \mathrm{I}-\mathrm{kalli}^{-}$ krein in normal plasma was associated with CI inhibitor, $35 \%$ with $\alpha_{2} \mathrm{M}$, and $13 \%$ with AT III and another inhibitor. The data also indicate that in the absence of $\mathrm{C} \overline{1}$ inhibitor, $67 \%$ of kallikrein in plasma was complexed to $\alpha_{2} \mathrm{M}$, whereas in $\alpha_{2} \mathrm{M}$-deficient plasma $84 \%$ of kallikrein was associated with $C \bar{l}$ inhibitor.

Contribution of $\alpha_{2} M, C \bar{I}$ inhibitor, and AT III to kallikrein inactivation in plasma: analysis by insolubilized immunopurified anti-inhibitor antibodies. To investigate the possibility that during its inactivation in plasma, kallikrein formed complexes that were not resistant to SDS, ${ }^{125} \mathrm{I}$-kallikrein was inactivated in plasma and subsequently passed over columns containing insolubilized antibodies against either $C \bar{l}$ inhibitor, $\alpha_{2} \mathrm{M}$, or AT III. $49 \%$ of the radioactivity present in plasma did not bind to any of the insolubilized anti-inhibitor columns, whereas only $0.2 \%$ bound to Sepharose 4B to which no anti-inhibitor antibodies were coupled. Of the specifically bound radiolabeled kallikrein, $55 \%$ was associated with $\mathrm{C} \overline{1}$ inhibitor, $41 \%$

TABLE I

Contribution of $\alpha_{2} M, C \bar{l}$ inhibitor, and Other Inhibitors, Including AT III, to Complex Formation with ${ }^{125}$ I-Kallikrein after Inactivation in Normal and Inhibitor-deficient Plasma

\begin{tabular}{lccc}
\hline & $\alpha_{2} \mathrm{M}$ & CI inhibitor & $\begin{array}{c}\text { Other inhibitors. } \\
\text { including AT III }\end{array}$ \\
\hline & & \multicolumn{2}{c}{$\%$} \\
$\begin{array}{l}\text { Normal plasma } \\
\text { Ci inhibitor-deficient }\end{array}$ & 35 & 52 & 13 \\
$\quad$ plasma & 67 & 0 & 33 \\
$\alpha_{2}$ M-deficient plasma & 0 & 84 & 16 \\
AT III-deficient & & & 7 \\
$\quad$ plasma & 23 & 70 & \\
\hline
\end{tabular}

with $\alpha_{2} \mathrm{M}$, and $4 \%$ with AT III. Control experiments indicated that in the eluate plasma fraction, no immunological detectable Cī inhibitor, $\alpha_{2} M$, or AT III was present after plasma had passed over the column containing the respective insolubilized antibody. In addition, all kallikrein amidolytic activity was removed from the plasma samples. To investigate the possibility that kallikrein-inhibitor complexes did not react with the appropriate anti-inhibitor antibodies, purified kallikrein was incubated with the purified inhibitors in a molar ratio of 10:1 and tested by double immunodiffusion and rocket immunoelectrophoresis by using the anti-inhibitor antibody. In each case it was demonstrated that the antibody precipitated with the kallikrein-inhibitor complex.

Kinetics of SDS-resistant complex formation between ${ }^{125} I$-kallikrein and $C I$ inhibitor, $\alpha_{2} M$, and $A T$ III during inactivation of kallikrein in plasma. To analyze complex formation between kallikrein and its inhibitors as a function of time during inactivation in plasma, ${ }^{125} \mathrm{I}$-prekallikrein was added to normal human plasma and subsequently incubated at $4^{\circ} \mathrm{C}$ with dextran sulfate. When maximum kallikrein activity was generated, the mixture was incubated at $37^{\circ} \mathrm{C}$. At different incubation times at $37^{\circ} \mathrm{C}$, samples were withdrawn, added to a SDS solution, and analyzed by 325\% gradient PAA slab gel electrophoresis. The dried gel was sliced and the radioactivity incorporated in the ${ }^{125}$ I-kallikrein-inhibitor complexes was counted. The formation of kallikrein-inhibitor complexes as a function of time is shown in Fig. 4. Upon incubation

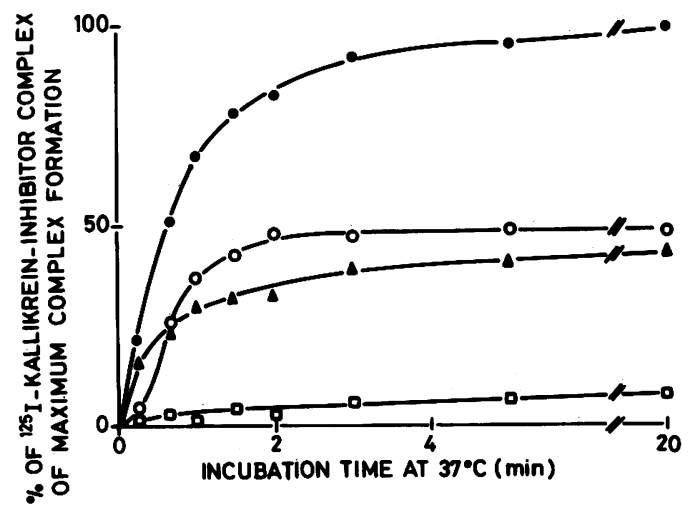

Figure 4 Kinetics of complex formation between ${ }^{125}$ I-kallikrein and $C \bar{I}$ inhibitor $(O), \alpha_{2} M(\Delta)$, and other protease inhibitors (ם), or total (ब) during inactivation in plasma. Complex formation between kallikrein and each inhibitor was analyzed at different times by SDS gradient PAA slab gel electrophoresis and plotted as percent radioactivity present in a kallikrein-inhibitor complex of the radioactivity associated with all kallikrein-inhibitor complexes at $20 \mathrm{~min}$ at $37^{\circ} \mathrm{C}$. 
at $37^{\circ} \mathrm{C}, \alpha_{2} \mathrm{M}$ immediately formed complexes with kallikrein. At the first time point $(t=20 \mathrm{~s})$, more kallikrein was bound to $\alpha_{2} \mathrm{M}$ than to Cī inhibitor. However, between $1 / 2$ and 2 min, complex formation between kallikrein and $C \bar{l}$ inhibitor increased at a higher rate than complex formation between $\alpha_{2} \mathrm{M}$ and kallikrein. During this time period, the rate of inactivation of kallikrein was relatively fast (Fig. 1A). The formation of the complexes with $M_{\mathrm{r}}=125,000-135,000$ slowly increased in time. Maximum complex formation was reached after $\sim 6 \mathrm{~min}$. $49 \%$ of the active ${ }^{125} \mathrm{I}$ kallikrein was then associated with Cī inhibitor, $43 \%$ with $\alpha_{2} \mathrm{M}$, and $8 \%$ with other inhibitors, including AT III.

Role of high-M, kininogen in the inactivation of kallikrein in plasma. As high- $M_{\mathrm{r}}$ kininogen was reported to decrease the inactivation rate of purified kallikrein by Cī inhibitor (25), $\alpha_{2} \mathrm{M}, \mathrm{AT}$ III, and $\alpha_{1}$ anti-trypsin (26), we compared the kinetics of kallikrein inactivation in high- $M_{\mathbf{r}}$ kininogen-deficient plasma with the inactivation in high- $M_{r}$ kininogendeficient plasma reconstituted with purified high- $M_{\mathrm{r}}$ kininogen. Therefore, equal volumes of kallikrein or kallikrein preincubated with different amounts of high- $M_{\mathrm{r}}$ kininogen were added to high- $M_{\mathrm{r}}$ kininogendeficient plasma and incubated at $37^{\circ} \mathrm{C}$. At different incubation times at $37^{\circ} \mathrm{C}$, samples were withdrawn and measured for the total kallikrein amidolytic activity. That the formation of a complex between kallikrein and high- $M_{\mathrm{r}}$ kininogen had indeed taken place was demonstrated by Laurell rocket immunoelectrophoresis with antiprekallikrein antibodies, under conditions described by Kerbiriou et al. (18). The presence of high- $M_{\mathrm{r}}$ kininogen did not influence the rate of kallikrein inactivation in plasma (Fig. 5). For this experiment, high- $M_{r}$ kininogen-deficient plasma was used from two unrelated congenitally high- $M_{\mathrm{r}}$ kininogendeficient patients. The same results were obtained with both plasmas, indicating that high- $M_{\mathrm{r}}$ kininogen does not protect kallikrein from inactivation in plasma.

\section{DISCUSSION}

The relative importance of plasma protease inhibitors in the inhibition of kallikrein in plasma was studied as well as the structure and nature of the interaction between kallikrein and its inhibitors during inactivation in plasma. Therefore, the kinetics of inactivation of kallikrein in protease inhibitor-depleted plasmas was investigated. Because plasma deficient in AT III or $\alpha_{2} \mathrm{M}$ was not available, artificially depleted plasmas were used in our study. $\alpha_{2} \mathrm{M}, \mathrm{C} \overline{\mathrm{I}}$ inhibitor, AT III, or both $\alpha_{2} \mathrm{M}$ and $\mathrm{C} \bar{l}$ inhibitor were removed by immunoadsorption by using insolubilized immunopurified anti-inhibitor antibodies. Factor XII-deficient plasma

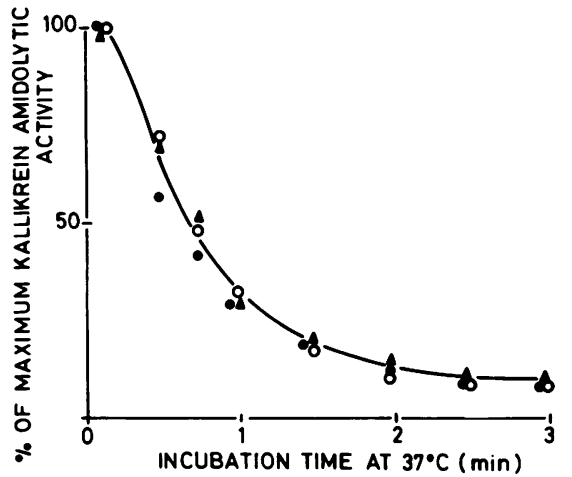

FiguRE 5 Inactivation of kallikrein in high- $M_{\mathrm{r}}$ kininogendeficient plasma. $12 \mu \mathrm{l}$ of kallikrein $(5.1 \mu \mathrm{g})$ was incubated for $5 \mathrm{~min}$ with $20.6 \mu \mathrm{l}$ of storage buffer (O), $10.3 \mu \mathrm{l}$ of high$M_{\mathrm{r}}$ kininogen $(7 \mu \mathrm{g})$, and $10.3 \mu \mathrm{l}$ of storage buffer $(\boldsymbol{\Lambda})$, or $20.6 \mu \mathrm{l}$ of high-M, kininogen $(14 \mu \mathrm{g},[0])$ at $4^{\circ} \mathrm{C}$ and subsequently added to $100 \mu \mathrm{l}$ of high- $M_{\mathrm{r}}$ kininogen-deficient plasma. Inactivation was followed at $37^{\circ} \mathrm{C}$ by measuring total kallikrein amidolytic activity of $30-\mu$ l aliquots at various times.

was used for the preparation of Cī inhibitor and $\alpha_{2} \mathrm{M}$ deficient plasma in order to exclude activation of the contact system. Removal of an inhibitor by this technique did not influence the level of the other inhibitors, whereas prekallikrein and high- $M_{r}$ kininogen levels of all deficient plasmas were in the normal range.

When kallikrein is inactivated in normal plasma at $37^{\circ} \mathrm{C}$, a plateau of $11 \%$ of its original activity is reached after $\sim 5 \mathrm{~min}$ (Fig. 1). This remaining activity is not inhibitable by SBTI, a plant inhibitor that rapidly inactivates the activity of kallikrein. Harpel (10) showed that kallikrein esterolytic activity present in plasma after $5 \mathrm{~min}$ incubation at $37^{\circ} \mathrm{C}$ in the presence of kaolin was only partly inhibitable by SBTI. Experiments performed with purified components indicated that kallikrein binds to $\alpha_{2} \mathrm{M}$ while retaining part of its esterolytic or amidolytic activity ${ }^{2}(10,26)$. Therefore, it is likely that the remaining kallikrein amidolytic activity seen in normal, Ci inhibitor-deficient, and AT III-deficient plasma is caused by $\alpha_{2} \mathrm{M}$-bound kallikrein. Further evidence is obtained from the fact that this remaining activity is not present in $\alpha_{2} \mathrm{M}$-deficient plasma. The absence of $\mathrm{C} \bar{l}$ inhibitor results in a markedly decreased rate of kallikrein inactivation and a $90 \%$ reduction in the pseudo first-order rate constant, whereas the rate constant is reduced to $63 \%$ in the absence of $\alpha_{2} \mathrm{M}$. The importance of these inhibitors can be demonstrated when both Cī inhibitor and $\alpha_{2} \mathrm{M}$ are absent. The pseudo first-order rate constant is then reduced to $2 \%$ of that in normal plasma. The absence of AT III in plasma appears to have a minor influence on the rate of kallikrein inactivation. However, when 
heparin is added to plasma deficient in both $\alpha_{2} \mathrm{M}$ and CI inhibitor, the inactivation rate constant for free kallikrein amidolytic activity increases approximately eight times, which suggests that AT III can play a role in the inactivation of kallikrein in plasma in the presence of heparin. This is also illustrated by the fact that addition of heparin to plasma from patients with hereditary angioneurotic edema was shown to increase the kallikrein inhibitory capacity of this plasma (27). Our observations indicate that $\mathrm{C} \overline{\mathrm{l}}$ inhibitor is responsible for the relatively rapid rate of kallikrein inactivation in plasma, whereas of all other protease inhibitors, only $\alpha_{2} \mathrm{M}$ appears to play a major role. These results agree with other reports that suggested that Cī inhibitor and $\alpha_{2} \mathrm{M}$ are important inactivators of plasma kallikrein $(9-15,25,26,28)$.

In plasma, kallikrein forms a number of complexes with apparent molecular weights in the range of $400,000-1,000,000,185,000$, and $125,000-135,000$. By using purified proteins and plasmas depleted of inhibitors, the complexes were identified. The complexes with molecular weights in the range of $400,000-$ $1,000,000$ were due to the formation of complexes between $\alpha_{2} \mathrm{M}$ and kallikrein; the complex at $M_{\mathrm{r}}$ $=185,000$ was the $C \bar{l}$ inhibitor-kallikrein complex. The complexes at $M_{\mathrm{r}}=125,000,130,000$, and 135,000 might be due to complex formation between kallikrein and AT III, because identical complexes were formed between purified kallikrein and AT III. Venneröd and coauthors (29) also showed formation of three SDS stable complexes between kallikrein and AT III, although the $M_{\mathrm{r}}$ values were slightly different from ours. During inactivation in AT III-deficient plasmas, kallikrein also formed complexes with $M_{\mathrm{r}}=125,000-135,000$, which were very similar to those seen in normal plasma. Therefore, a protease inhibitor other than $C \bar{l}$ inhibitor, $\alpha_{2} \mathrm{M}$, and AT III might contribute to the inactivation of kallikrein in plasma. $\alpha_{1}$-antitrypsin and $\alpha_{2}$-antiplasmin were also reported to be inhibitors of plasma kallikrein $(26,30)$. Therefore, the complexes with $M_{\mathrm{r}}=125,000-135,000$ might also include kallikrein$\alpha_{1}$-antitrypsin and/or kallikrein- $\alpha_{2}$-antiplasmin complexes.

Approximately $45 \%$ of the radiolabeled kallikrein behaved as uncomplexed kallikrein on the SDS gel and might represent inactive kallikrein caused by the radiolabeling procedure or kallikrein noncovalently complexed to one or more inhibitors. When the data were corrected for this, $35 \%$ of kallikrein was found to form a complex with $\alpha_{2} \mathrm{M}, 52 \%$ with $\mathrm{C} \overline{1}$ inhibitor, and $13 \%$ with inhibitors other than $\mathrm{C} \overline{1}$ inhibitor and $\alpha_{2} \mathrm{M}$. Because complexes that dissociate in the presence of SDS are not detected by this method, we used insolubilized immunopurified anti-Cl̄ inhibitor, $\alpha_{2} \mathrm{M}$, or
AT III antibodies to determine the contribution of Cī inhibitor, $\alpha_{2} \mathrm{M}$, and AT III to kallikrein inactivation in plasma. $49 \%$ of the radiolabeled kallikrein did not bind to any insolubilized anti-inhibitor antibody. No kallikrein activity was detected in the eluate of a column containing the insolubilized antibodies against Cī inhibitor, $\alpha_{2} \mathrm{M}$ and, AT III, indicating that no active kallikrein was dissociated from a complex with inhibitor(s). This suggests that the portion of the radiolabeled kallikrein that did not bind to the columns represents inactive kallikrein. The relative contribution of the inhibitors to kallikrein inactivation was similar to that detected with SDS gradient PAA gel electrophoresis. This suggests that only covalent complexes are formed between kallikrein and its inhibitors in plasma. Recently, Schapira et al. (28) reported kinetic studies of kallikrein inactivation in plasma. The contribution of $\mathrm{C} \overline{1}$ inhibitor and $\alpha_{2} \mathrm{M}$ to kallikrein inactivation in undiluted plasma was calculated to be 58 and $38 \%$, respectively, which agrees with the results obtained in this study.

When the formation of complexes of kallikrein with the inhibitors was followed in the time during inactivation of kallikrein in plasma at $37^{\circ} \mathrm{C}$, the Cî inhibitor-kallikrein complex was formed at a higher rate than the $\alpha_{2} \mathrm{M}$-kallikrein complex. But $\alpha_{2} \mathrm{M}$ immediately formed complexes, whereas $\mathrm{C} \overline{1}$ inhibitor showed a sigmoidal increase of complex formation. This might be an effect of temperature, as Ci inhibitor is probably more sensitive to low temperature than is $\alpha_{2} \mathrm{M}$. Maximum complex formation was observed after 5-6 min, correlating well with maximum kallikrein inhibition (Fig. 1A).

When using purified proteins it was reported that high- $M_{\mathrm{r}}$ kininogen reduced the rate of kallikrein inactivation by CĪ inhibitor (25), $\alpha_{2} \mathrm{M}, \mathrm{AT}$ III, and $\alpha_{1}$ antitrypsin (26) as a result of complex formation between kallikrein and high- $M_{\mathrm{r}}$ kininogen. Analysis of the kinetic data yielded a dissociation constant of 0.75 $\mu \mathrm{M}$ for this complex. Because high- $M_{\mathrm{r}}$ kininogen circulates in plasma complexed to prekallikrein (31) or kallikrein (18), this observation might imply that high$M_{r}$ kininogen also influences the rate of kallikrein inactivation by its inhibitors in plasma. Therefore, we studied the inactivation rate of kallikrein in high- $M_{r}$ kininogen-deficient plasma. Addition of high- $M_{\mathrm{r}}$ kininogen to this plasma (final concentration 0.53 or 1.06 $\mu \mathrm{M})$ appeared to have no effect on the rate of kallikrein inactivation. Laurell rocket immunoelectrophoresis using anti-prekallikrein antibodies showed that high$M_{\mathrm{r}}$ kininogen formed a complex with kallikrein under these conditions. Therefore, it seems unlikely that high- $M_{\mathrm{r}}$ kininogen plays a protective role in relation to kallikrein inactivation in plasma. 
tective role in relation to kallikrein inactivation in plasma.

Cì inhibitor is the only control protein capable of interacting with $\mathrm{Cl}_{\mathbf{l}}(32)$ and is reported to be a primary plasma protein inhibitor of activated Factor XII $(33,34)$. Therefore, one might anticipate that if the complement and the contact systems are simultaneously activated, $\mathrm{C} \overline{\mathrm{l}}$ inhibitor levels decrease, and as a result $\alpha_{2} \mathrm{M}$ will play a more predominant role in the inactivation of kallikrein. In plasma of hereditary angioedema (HAE) patients, who are known to be genetically deficient in $\mathrm{C} \overline{\mathrm{l}}$ inhibitor, $\alpha_{2} \mathrm{M}$ is probably the main control protein for kallikrein. However, Curd et al. (35) recently showed that suction-induced blister fluids of HAE patients contained large amounts of active kallikrein, whereas similar blister fluids obtained from normal individuals did not. This observation suggests that activation of the Hageman factor-dependent pathway occurs in the tissues of $\mathrm{HAE}$ patients, and once activated, active kallikrein persists in these tissues. Therefore, at least in tissues, it seems unlikely that in the absence of $\mathrm{C} \overline{1}$ inhibitor, kallikrein activity can be fully controlled by $\alpha_{2} \mathrm{M}$ and other minor kallikrein inhibitors as AT III.

\section{ACKNOWLEDGMENTS}

The advice of Dr. John H. Griffin is gratefully acknowledged. The skillful technical assistance of Fréke J. A. Keus is most appreciated. Thanks are also due to Annemieke Beijer for typing this manuscript.

This work was supported by grant 13-30-33 from the Netherlands Organization for the Advancement of Pure Research (ZWO).

\section{REFERENCES}

1. Webster, M. E. 1970. Recommendations for nomenclature and units. In Handbook of Experimental Pharmacology. E. G. Erdös, editor. Springer-Verlag New York, Inc. 25: 659-665.

2. Margolis, J. 1958. Activation of plasma by contact with glass: evidence for a common reaction which releases plasma kinins and initiates coagulation. J. Physiol. (Lond.). 144: 1-22.

3. Werle, E. 1970. Discovery of the most important kallikreins and kallikrein inhibitors. In Handbook of Experimental Pharmacology. E. G. Erdös, editor. SpringerVerlag New York, Inc. 25: 1-6.

4. Wuepper, K. D. 1973. Prekallikrein deficiency in man. J. Exp. Med. 138: 1345-1355.

5. Weiss, A. S., J. I. Gallin, and A. P. Kaplan. 1974. Fletcher factor deficiency. A diminished rate of Hageman factor activation caused by absence of prekallikrein with abnormalities of coagulation, fibrinolysis, chemotactic activity, and kinin generation. J. Clin. Invest. 53: 622633.

6. Colman, R. W. 1969. Activation of plasminogen by plasma kallikrein. Biochem. Biophys. Res. Commun. 35: 273-279.
7. Mandle, R., Jr., and A. P. Kaplan. 1977. Hageman factor substrates. Human plasma prekallikrein: mechanism of activation by Hageman factor and participation in Hageman factor-dependent fibrinolysis. J. Biol. Chem. 252: 6097-6104.

8. Bouma, B. N., L. A. Miles, G. Beretta, and J. H. Griffin. 1980. Human plasma prekallikrein. Studies of its activation by activated Factor XII and of its inactivation by diisopropyl phosphofluoridate. Biochemistry. 19: 11511160 .

9. Ratnoff, O. D., J. Pensky, O. Ogston, and G. B. Naff. 1969. The inhibition of plasmin, plasma kallikrein, plasma permeability factor, and the CIIr subcomponent of the first component of complement by serum Cí esterase inhibitor. J. Exp. Med. 129: 315-331.

10. Harpel, P. C. 1970. Human plasma $\alpha_{2}$-macroglobulin. An inhibitor of plasma kallikrein. J. Exp. Med. 132: 329352.

11. Gigli, I., J. W. Mason, R. W. Colman, and K. F. Austen. 1970. Interaction of plasma kallikrein with the $C \bar{I}$ inhibitor. J. Immunol. 104: 574-581.

12. McConnell, D. J. 1972. Inhibitors of kallikrein in human plasma. J. Clin. Invest. 51: 1611-1623.

13. Fritz, H., G. Wunderer, K. Kummer, N. Heimburger, and E. Werle. 1972. $\alpha_{1}$-antitrypsin und Cí-inactivator. Progressiv inhibitoren für Serumkallikreine von Mensch und Schwein. Hoppe-Seyler's Z. Physiol. Chem. 353: 906-910.

14. Trumpi-Kalshoven, M. M., and C. Kluft. 1978. Cī inhibitor: the main inhibitor of human plasma kallikrein. In Current concepts in kinin research. Advances in the biosciences. G. L. Haberland and U. Hamberg, editors. Pergamon Press, Inc., New York. 17: 93-101.

15. Gallimore, M. J., E. Amundsen, M. Larsbraaten, K. Lyngaas, and E. Fareid. 1979. Studies on plasma inhibitors of plasma kallikrein using chromogenic peptide substrate assays. Thromb. Res. 16: 695-703.

16. Burrowes, C. E., F. M. Habal, and H. Z. Movat. 1975. The inhibition of human plasma kallikrein by antithrombin III. Thromb. Res. 7: 175-183.

17. Venneröd, A. M., and K. Laake. 1975. Inhibition of purified plasma kallikrein by antithrombin III and heparin. Thromb. Res. 7: 223-226.

18. Kerbiriou, D. M., B. N. Bouma, and J. H. Griffin. 1980. Immunochemical studies of human high molecular weight kininogen and of its complexes with plasma prekallikrein or kallikrein. J. Biol. Chem. 255: 3952-3958.

19. van der Graaf, F., G. Tans, B. N. Bouma, and J. H. Griffin. 1982. Isolation and functional properties of the heavy and light chains of human plasma kallikrein. $J$. Biol. Chem. 257. In press.

20. Kerbiriou, D. M., and J. H. Griffin. 1979. Human high $M_{\mathrm{r}}$ kininogen. Studies of structure function relationships and of proteolysis of the molecule occurring during contact activation of plasma. J. Biol. Chem. 254: 1202012027.

21. van der Graaf, F., J. F. A. Keus, H. A. A. Vlooswijk, and B. N. Bouma. 1982. The contact activation mechanisms in human plasma. Activation induced by dextran sulfate. Blood. 59: 1225-1233.

22. Bolton, A. E., and W. M. Hunter. 1973. The labelling of proteins to high specific radioactivities by conjugation to a ${ }^{125}$ I-containing acylating agent. Biochem. J. 133:
$529-539$.

23. Laurell, C. B. 1966. Quantitative estimation of proteins 
by electrophoresis in agarose gel containing antibodies. Anal. Biochem. 15: 45-52.

24. Laemmli, U. K. 1970. Cleavage of structural proteins during the assembly of the head of bacteriophage T4. Nature (Lond.). 227: 680-685.

25. Schapira, M., C. F. Scott, and R. W. Colman. 1981. Protection of human plasma kallikrein from inactivation by Cì inhibitor and other protease inhibitors. The role of high molecular weight kininogen. Biochemistry. 20: 2738-2743.

26. Schapira, M., C. F. Scott, A. James, L. D. Silver, F. Kueppers, H. L. James, and R. W. Colman. 1982. High molecular weight kininogen or its light chain protects human plasma kallikrein from inactivation by plasma protease inhibitors. Biochemistry. 21: 567-572.

27. Lahari, B., A. Bagdasarian, B. Mitchell, R. C. Talamo, R. W. Colman, and R. D. Rosenberg. 1976. Antithrombin-heparin cofactor: an inhibitor of plasma kallikrein. Arch. Biochem. Biophys. 175: 737-747.

28. Schapira, M., C. F. Scott, and R. W. Colman. 1982. Contribution of plasma protease inhibitors to the inactivation of kallikrein in plasma. J. Clin. Invest. 69: 462-468.

29. Venneröd, A. M., K. Laake, A. K. Solberg, and S. Strömland. 1976. Inactivation and binding of human plasma kallikrein by antithrombin III and heparin. Thromb. Res. 9: 457-466.

30. Saito, H., G. H. Goldsmith, M. Moroi, and N. Aoki. 1979. Inhibitory spectrum of $\alpha_{2}$-plasmin inhibitor. Proc. Natl. Acad. Sci. USA. 76: 2013-2017.

31. Mandle, R. J., R. W. Colman, and A. P. Kaplan. 1976. Identification of prekallikrein and high molecular weight kininogen as a complex in human plasma. Proc. Natl. Acad. Sci. USA. 73: 4179-4183.

32. Ziccardi, R. J. 1981. Activation of the early components of the classical complement pathway under physiologic conditions. J. Immunol. 126: 1769-1773.

33. Forbes, D. C., J. Pensky, and O. D. Ratnoff. 1970. Inhibition of activated Hageman Factor and activated plasma thromboplastin antecedent by purified serum Cī inactivator. J. Lab. Clin. Med. 76: 809-815.

34. Schreiber, A. D., A. P. Kaplan, and K. F. Austen. 1973. Inhibition by CîINH of Hageman factor fragment activation of coagulation, fibrinolysis, and kinin generation. J. Clin. Invest. 52: 1402-1409.

35. Curd, J. G., L. J. Prograis, Jr., and C. G. Cochrane. 1980. Detection of active kallikrein in induced blister fluids of hereditary angioedema patients. J. Exp. Med. 152: 742-747. 